\title{
BMJ open Common psychosocial stressors in middle-aged women related to longstanding distress and increased risk of Alzheimer's disease: a 38-year longitudinal population study
}

\author{
Lena Johansson, ${ }^{1}$ Xinxin Guo, ${ }^{1}$ Tore Hällström, ${ }^{1,2}$ Maria C Norton, ${ }^{3}$ \\ Margda Waern, ${ }^{1}$ Svante Östling, ${ }^{1}$ Calle Bengtsson, ${ }^{4}$ Ingmar Skoog ${ }^{1}$
}

To cite: Johansson L, Guo X, Hällström $\mathrm{T}$, et al. Common psychosocial stressors in middle-aged women related to longstanding distress and increased risk of Alzheimer's disease: a 38year longitudinal population study. BMJ Open 2013;3: e003142. doi:10.1136/ bmjopen-2013-003142

- Prepublication history for this paper is available online. To view these files please visit the journal online (http://dx.doi.org/10.1136/ bmjopen-2013-003142).

Received 30 April 2013 Revised 5 July 2013 Accepted 8 July 2013

For numbered affiliations see end of article.

\section{Correspondence to} Lena Johansson; lena. johansson@neuro.gu.se

\section{ABSTRACT}

Objective: To study the relation among psychosocial stressors, long-standing distress and incidence of dementia, in a sample of women followed from midlife to late life.

Design: Prospective longitudinal population study.

Setting: The analyses originate from the prospective population study of women in Gothenburg, Sweden, a representative sample of women examined in 1968 (participation rate 90\%) and re-examined in 1974, 1980, 1992, 2000 and 2005.

Participants: 800 women born in 1914, 1918, 1922 and 1930 who were systematically selected for a psychiatric examination at baseline, in 1968.

Primary and secondary outcome measures: 18 psychosocial stressors (eg, divorce, widowhood, work problems and illness in relative) were obtained at baseline. Symptoms of distress were measured according to a standardised question at each study wave. Dementia was diagnosed according to Diagnostic and Statistical Manual of Mental Disorders (DSM-III-R) criteria based on information from neuropsychiatric examinations, informant interviews, hospital records, and registry data, and measured through the whole study period.

Results: During the 37 years of follow-up, 153 women developed dementia (104 of those had Alzheimer's disease (AD)). Number of psychosocial stressors in 1968 was associated (HR, 95\% Cl) with higher incidence of dementia $(1.15,1.04$ to 1.27$)$ and $\operatorname{AD}(1.20,1.07$ to 1.35$)$ between 1968 and 2005 , in multivariate Cox regressions. Number of psychosocial stressors in 1968 was also associated $(\mathrm{OR}, 95 \% \mathrm{Cl})$ with distress in 1968 (1.48, 1.32 to 1.67), 1974 (1.31, 1.17 to 1.46$), 1980$ (1.27, 1.11 to 1.45$), 2000$ (1.39, 1.14 to 1.70$)$ and 2005 (1.35, 1.02 to 1.79$)$, in multivariate logistic regressions. Number of psychosocial stressors (HR $1.17,95 \% \mathrm{Cl} 1.03$ to 1.33 ) and long-standing distress (1968-1974-1980) (HR $1.58,95 \% \mathrm{Cl} 1.03$ to 2.45 ) were independently associated with AD.

Conclusions: Our study shows that common psychosocial stressors may have severe and

\section{ARTICLE SUMMARY}

Article focus

- To study the relation between psychosocial stressors, long-standing distress and incidence of dementia, in a sample of women followed over 38 years, from midlife to late life.

Key messages

- The study shows that the number of psychosocial stressors, measured in middle-aged women, was related to distress and incidence of $\mathrm{AD}$ almost four decades later.

- The study also shows that the association between number of psychosocial stressors and $A D$ was independent of long-standing perceived distress.

Strengths and limitations of this study

- Midlife report of psychosocial stressors occurring long before dementia onset, the long follow-up period, the representative population and that multiple sources of information were used to detect and diagnose dementia.

- The rating of stressors was related to the last year for some stressors and at any time before 1968 for other stressors. Some stressors were of a short duration, while others were chronic and lasting for many years. We only have information on a limited number of psychosocial stressors in our population. Individuals have different capacities to cope with stress and thus react differently when exposed to the same stressor. We did not have an individual weighting of the included stressors.

long-standing physiological and psychological consequences. However, more studies are needed to confirm these results and investigate whether more interventions such as stress management and behavioural therapy should be initiated in individuals who have experienced psychosocial stressors. 


\section{INTRODUCTION}

Experiences of severe psychological stressors in adulthood (eg, combat, ${ }^{1}$ natural disasters ${ }^{2}$ and the Holocaust ${ }^{3}$ ) are known to influence mental and physical health decades later. Mild psychosocial stressors are common and could be considered as part of normal life. The long-term consequences of these more common stressors remain unclear. Epidemiological studies in the elderly with the follow-ups of less than 10 years have reported that history of early parental death, ${ }^{4-6}$ death of spouse $^{7}$ and psychosocial risk factors in childhood ${ }^{6}$ increase the risk of dementia or Alzheimer's disease (AD). One explanation for the associations is that traumatic experiences may perhaps give rise to long-standing chronic distress many years after the trauma. This may lead to a cumulative burden to the brain with dysregulation in neuroendocrine systems. ${ }^{8-10}$ A study among Holocaust survivors found that higher levels of stress hormones remained decades after the traumatic experience. ${ }^{8}$

We have previously reported that long-standing distress in midlife leads to long-term consequences decades later, such as increased risk of dementia, $\mathrm{AD}^{11}$ and structural brain changes. ${ }^{12}$ To our knowledge, no population study has examined whether number of psychosocial stressors in midlife increase the risk of dementia in late life, and whether this is modified by long-standing distress.

The aim of this study was to examine whether common psychosocial stressors in midlife were related to distress, late-life dementia and $\mathrm{AD}$, in women followed over 38 years. We further aimed to examine whether experiences of psychosocial stressors modify the previously reported association between long-standing midlife distress and AD.

\section{METHODS}

\section{Study population}

This study is part of the Prospective Population Study of Women in Gothenburg, Sweden, ${ }^{13}{ }^{14}$ which was initiated in 1968 with an examination of 1462 women (participation rate 90\%) born in 1908, 1914, 1918, 1922 and 1930. The individuals were systematically sampled from the Swedish Population Registry based on specific birth dates in order to yield a representative sample at the ages studied. The follow-ups were performed in 1974 , 1980, 1992, 2000 and 2005 with participation rates among survivors of $91 \%, 83 \%, 70 \%, 71 \%$ and $70 \%$, respectively. The informed consent was obtained from all participants, in accordance with the provision of the Helsinki Declaration.

The current study included a subsample of 800 women who were systematically selected for a psychiatric examination in 1968. The women were aged 38 years $(n=111)$, 46 years $(n=309), 50$ years $(n=290)$ and 54 years $(n=90)$. Among them, 713 participated in the follow-up examination in 1974, 639 in 1980, 472 in 1992, 368 in 2000 and 296 in 2005 . Losses were mainly due to death.
Assessment of psychosocial stressors

At baseline 1968, 18 predefined psychosocial stressors were asked and rated by a psychiatrist during the psychiatric examination. These included divorce, widowhood, serious problem in children (eg, physical illness, death and abuse), extramarital childbirth, mental illness in spouse or first-degree relative, alcohol abuse in spouse or first-degree relative, physical illness or social problems related to husband, receiving help from Social Security, problem related to husband's or own work (eg, lost work) and limited social network. Some of the stressors (physical illness, mental illness and alcohol abuse in spouse; serious problem and mental illness in child; work-related problems and limited social network) were rated in the last year before examination in 1968. The others were rated as occurring at any time prior to the examination in 1968.

\section{Assessment of distress}

Symptoms of distress were rated according to a standardised question in 1968, 1974, 1980, 2000 and 2005. The question was worded identically at each examination; "Have you experienced any period of distress (1 month or longer) in relation to circumstances in everyday life, such as work, health or family situation? Distress refers to feelings of irritability, tension, nervousness, fear, anxiety or sleep disturbances." Participants were asked to choose between; $0=$ have never experienced any period of distress; $1=$ have experienced period/s of distress more than 5 years ago; $2=$ have experienced one period of distress during the last 5 years; $3=$ have experienced several periods of distress during the last 5 years; $4=$ have experienced constant distress during the last year or 5 =have experienced constant distress during the last 5 years. In the current study, distress is defined as a rating of 3-5.

\section{Psychiatric examinations}

The psychiatric examinations were conducted in 1968 , 1974, 1980 and 1992 by psychiatrists and in 2000 and 2005 by experienced psychiatric research nurses. The examinations were semistructured and included a comprehensive neuropsychiatric examination and an extensive battery of neuropsychiatric tests. ${ }^{15}$ Close informant interviews were conducted in 1992, 2000 and 2005. These included questions about changes in behaviour and intellectual functions and, in cases of dementia, age of onset and disease course. ${ }^{15}$ Medical records were collected from all inpatient and outpatient departments and general practitioners' offices in Gothenburg. The Swedish Hospital Discharge Registry provided diagnostic information for all individuals discharged from hospitals on a nationwide basis since 1978 .

\section{Diagnosis of dementia}

The diagnosis of dementia was based on information from psychiatric examinations, close informant interviews, medical record examinations and the Swedish 
Hospital Discharge Registry. The diagnostic procedures have been described in detail previously. ${ }^{15}$ Dementia diagnosis at each examination was made according to the Diagnostic and Statistical Manual of Mental Disorders (DSM-III-R) based on the combined information from the psychiatric examination and the close informant interview. Dementia diagnoses for individuals lost to the follow-up were based on information from medical records evaluated by geriatric psychiatrists in consensus conferences, and information from the Swedish Hospital Discharge Registry. ${ }^{16}$

$\mathrm{AD}$ was diagnosed according to the criteria of the National Institute of Neurological and Communicative Disorders and Stroke and the Alzheimer's Disease and Related Disorders Association (NINCDS-ADRDA). ${ }^{17}$ The criteria for vascular dementia (VaD) were similar to the criteria proposed by the National Institute of Neurological Disorders and Stroke and the Association Internationale pour la Recherce et l'Enseignement en Neurosciences (NINDS-AIREN). ${ }^{18}$ VaD was thus diagnosed when there was a temporal relationship (within 1 year) between a history of acute focal neurological symptoms and signs (haemiparesis or motor aphasia) and the first symptoms of dementia. Other dementias were diagnosed when other causes were likely to have caused the dementia. Person-years were calculated from the date of the baseline examination to (1) the time of dementia onset; (2) the date of death; (3) the date of the last follow-up examination for participants in 2005 or (4) 31 December 2006 for surviving drop-outs.

\section{Potential confounders and mediators}

Information on education, socioeconomic status, marital status and work status was obtained at the examination in 1968, and information on blood pressure, antihypertensive medication use, coronary heart disease (CHD), diabetes mellitus, stroke, waist and hip circumferences, cigarette smoking and wine consumption was obtained at the examinations in 1968, 1974 and 1980. Education was dichotomised as compulsory ( 6 years for those born during 1914-1922 and 7 years for those born in 1930) versus more than compulsory education. Socioeconomic status was based on husband's occupation for married women, and own occupation for unmarried women and was defined as higher middle, lower middle, skilled workers and unskilled workers. ${ }^{19}$ Marital status was classified as married and/or cohabiting versus single. Work status was measured as full-time work and/or part-time work versus no work outside home. Hypertension was defined as systolic blood pressure of $160 \mathrm{~mm} \mathrm{Hg}$ or more, and/or diastolic blood pressure $95 \mathrm{~mm} \mathrm{Hg}$ or more and/or taking antihypertensive medication. CHD was defined as angina pectoris according to the Rose criteria $^{20}$ or documented history of myocardial infarction. Diabetes mellitus was defined as a diagnosis told by a doctor, death certificates, being on antidiabetes drugs or having two fasting blood glucose values of $7 \mathrm{mmol} / \mathrm{L}$ or more. Stroke was diagnosed based on information from the examinations and the Swedish Hospital Discharge Registry. High waist-to-hip ratio was defined as a ratio of waist and hip circumferences over 0.85 . Cigarette smoking was defined as never, former or current smoker. Wine consumption was classified as none, less than once weekly and once weekly or more.

\section{Statistical analyses}

Logistic regressions were used to analyse the associations between number of psychosocial stressors in 1968 and report of distress in 1968, 1974, 1980, 2000 and 2005. The results are presented as ORs and 95\% CIs in three separate models. The first model adjusts for age only. The second model adjusts for age, education, socioeconomic status, marital status, work status, hypertension, CHD, stroke, diabetes mellitus, waist-to-hip ratio, smoking and wine consumption. The third model adjusts for age and psychiatric family history, that is, mental illness in mother, father and/or sibling. (These three variables were then not counted as psychosocial stressors.)

Cox regressions were used to study the associations between number of psychosocial stressors and incidence of dementia and dementia subtypes. Associations are presented as HRs and 95\% CIs, and model 1-3 adjust for the same covariates as listed above. The fourth model adjusts for age and long-standing midlife distress (ie, distress in all examinations 1968-1974-1980). Two interaction models were also added; (1) number of stressors $\times$ psychiatric family in relation to $\mathrm{AD}$ and (2) number of stressors $\times$ long-standing distress in relation to $\mathrm{AD}$. Finally, we examined the associations between longstanding midlife distress and psychosocial stressors in relation to $\mathrm{AD}$ before and after age 75 .

\section{RESULTS}

Characteristics of the 800 participants are given in table 1 . The proportion of women who reported specific life stressors in 1968 are shown in table 2. Twenty-five per cent of the women reported one psychosocial stressor, 23\% reported two stressors, $20 \%$ three stressors and $16 \%$ four or more stressors. The most frequently reported psychosocial stressor was mental illness in first-degree relative (mother 27\%, father 19\% and sibling 32\%).

Four hundred and twenty-five participants died during the follow-up (mean age 79 years). From 1968 to 2006, 153 (19.1\%) women developed dementia during 25131 person-years of follow-up, including 104 with $\mathrm{AD}, 35$ with $\mathrm{VaD}$ and 14 with other dementias. The mean time from the baseline examination in 1968 to dementia onset was 29 years (26 had dementia onset before 1992, 73 between 1992 and 2000 and 54 after 2000). Mean age of dementia onset was 78 years ( 45 had dementia onset before age 75 years and 108 after age 75 years).

Number of psychosocial stressors in 1968 was associated with distress in 1968, 1974, 1980, 2000 and 2005, after adjustment for potential confounders (table 3). 
Table 1 Characteristics of the study sample $(\mathrm{N}=800)$

\begin{tabular}{|c|c|c|}
\hline & $\mathbf{N}$ & Per cent \\
\hline \multicolumn{3}{|l|}{ Birth year (age) } \\
\hline 1914 (54 years) & 89 & 11.1 \\
\hline 1918 (50 years) & 291 & 36.4 \\
\hline 1922 (46 years) & 309 & 38.6 \\
\hline 1930 (38 years) & 111 & 13.9 \\
\hline \multicolumn{3}{|l|}{ Education* } \\
\hline Compulsory & 600 & 75.0 \\
\hline More than compulsory & 200 & 25.0 \\
\hline \multicolumn{3}{|l|}{ Socioeconomic status ${ }^{*}$} \\
\hline Upper middle & 161 & 20.2 \\
\hline Lower middle & 267 & 33.4 \\
\hline Skilled workers & 209 & 26.1 \\
\hline Unskilled workers & 163 & 20.4 \\
\hline \multicolumn{3}{|l|}{ Marital status* } \\
\hline Married & 638 & 79.8 \\
\hline Cohabited (not married) & 94 & 11.7 \\
\hline Living alone (not married) & 68 & 8.5 \\
\hline \multicolumn{3}{|l|}{ Work status* } \\
\hline Full-time work & 270 & 33.8 \\
\hline Part-time work & 258 & 32.3 \\
\hline No work outside home & 272 & 34.0 \\
\hline Hypertension† & 144 & 18.0 \\
\hline Coronary heart disease $†$ & 74 & 9.3 \\
\hline Diabetes mellitus $†$ & 24 & 3.0 \\
\hline Stroke† & 5 & 0.5 \\
\hline Smoking† & 341 & 42.6 \\
\hline Wine consumption & 246 & 30.8 \\
\hline High waist-to-hip ratiot & 210 & 26.3 \\
\hline
\end{tabular}

ORs were similar after further adjustment for psychiatric family history in model 3 . Number of psychosocial stressors was associated with long-standing midlife distress (ie, distress in 1968-1974-1980) both in later born cohorts, born 1922 and 1930, (multiadjusted OR 1.32, 95\% CI 1.14 to 1.52 ) and earlier born cohorts, born 1914 and 1918 (multiadjusted OR 1.58, 95\% CI 1.30 to 1.94).

Number of psychosocial stressors in 1968 was associated with higher incidence of AD (HR 1.21, 95\% CI 1.08 to 1.36 ) and all-type dementia (HR $1.15,95 \%$ CI 1.05 to 1.27 ; table 4 ). The associations remained after adjusting for multiple confounders in model 2, psychiatric family history in model 3 and long-standing distress (ie, distress in 1968-1974-1980) in model 4. In the fourth model, long-standing distress (HR 1.58, 95\% CI 1.01 to 2.46) and number of psychosocial stressors (HR $1.17,95 \%$ CI 1.02 to 1.33 ) were independently associated with $\mathrm{AD}$. There were no interactions between number of stressors and psychiatric family history in relation to AD (age-adjusted HR 1.05, 95\% CI 0.75 to 1.45 , $\mathrm{p}=0.79$ ) or between number of stressors and longstanding distress in relation to $\mathrm{AD}$ (age-adjusted $\mathrm{HR}$ $1.04,95 \%$ CI 0.77 to $1.40, \mathrm{p}=0.82$ ). The association between number of psychosocial stressors and incidence
Table 2 Prevalence of psychosocial stressors in women in $1968(\mathrm{~N}=800)$

\begin{tabular}{|c|c|c|}
\hline & $\mathbf{N}$ & Per cent \\
\hline Physical illness in spouse & 62 & 7.8 \\
\hline Mental illness in spouse & 98 & 12.3 \\
\hline Alcohol abuse in spouse & 55 & 6.9 \\
\hline Social problem in spouse & 81 & 10.1 \\
\hline Work related problems in spouse & 32 & 4.0 \\
\hline Serious problem in children & 70 & 8.8 \\
\hline Mental illness in child & 139 & 17.4 \\
\hline Mental illness in father & 151 & 18.9 \\
\hline Alcohol abuse in father & 100 & 12.5 \\
\hline Mental illness in mother & 212 & 26.5 \\
\hline Mental illness in sibling & 255 & 31.9 \\
\hline Alcohol abuse in sibling & 79 & 9.9 \\
\hline Divorced & 65 & 8.1 \\
\hline Widowed & 34 & 4.3 \\
\hline Limited social contacts & 53 & 6.6 \\
\hline Work related problems & 19 & 2.4 \\
\hline Received help from social security & 10 & 1.3 \\
\hline Extramarital childbirth & 84 & 10.5 \\
\hline \multicolumn{3}{|l|}{ Number of psychosocial stressors } \\
\hline 0 psychosocial stressor & 149 & 18.6 \\
\hline 1 psychosocial stressor & 197 & 24.6 \\
\hline 2 psychosocial stressors & 184 & 23.0 \\
\hline 3 psychosocial stressors & 143 & 19.9 \\
\hline 4 psychosocial stressors & 69 & 8.6 \\
\hline$\geq 5$ psychosocial stressors & 58 & 7.2 \\
\hline
\end{tabular}

of $\mathrm{AD}$ were similar in those with early onset $\mathrm{AD}$ (aged $<75$ years; multiadjusted HR $1.25,95 \%$ CI 1.02 to 1.54 ) and late onset $\mathrm{AD}$ (aged $\geq 75$ years; multiadjusted HR $1.19,95 \%$ CI 1.03 to 1.38 ). There were no visible associations between number of psychosocial stressors and $\mathrm{VaD}$ in any of the models.

\section{DISCUSSION}

We found that number of common psychosocial stressors in midlife was associated with incidence of late-life dementia, especially $\mathrm{AD}$, in a population-based sample of women followed for 38 years. The associations remained when controlling for long-standing distress. We also found that number of psychosocial stressors in 1968 was related to increased level of distress at every examination conducted between 1968 and 2005.

We have previously reported that long-standing distress in midlife increase risk of $\mathrm{AD}^{11}$ and structural brain changes. ${ }^{12}$ These findings are now extended by showing that number of psychosocial stressors and report of distress independently predicted $\mathrm{AD}$, that is, increased distress could not completely explain the association between midlife stressors and dementia. One reason for this is that individuals respond differently to psychosocial stressors. Thus, biological responses may develop as a reaction to psychosocial stressors also in individuals who do not experience or report increased distress in association to the stressor. 
Table 3 Number of psychosocial stressors in 1968 in relations to report of distress in 1968, 1974, 1980, 2000 and 2005

\begin{tabular}{lllll}
\hline & Cases, $\mathbf{n}(\%)$ & Model 1 & Model 2 & Model 3 \\
\hline Distress in 1968 & $148(18.5)$ & $1.46(1.30$ to 1.63$)$ & $1.49(1.31$ to 1.70$)$ & $1.61(1.22$ to 2.13$)$ \\
Distress in 1974 & $161(20.1)$ & $1.31(1.18$ to 1.46$)$ & $1.33(1.17$ to 1.50$)$ & $1.23(1.05$ to 1.44$)$ \\
Distress in 1980 & $88(11.0)$ & $1.26(1.10$ to 1.43$)$ & $1.26(1.08$ to 1.47$)$ & $1.22(1.00$ to 1.50$)$ \\
Distress in 2000 & $49(6.1)$ & $1.41(1.17$ to 1.72$)$ & $1.40(1.13$ to 1.74$)$ & $1.24(0.95$ to 1.64$)$ \\
Distress in 2005 & $39(2.6)$ & $1.37(1.05$ to 1.80$)$ & $1.35(1.00$ to 1.85$)$ & $1.50(1.05$ to 2.20$)$ \\
\hline
\end{tabular}

Logistic regression analyses presented as ORs with 95\% Cls; model 1 adjust for age; model 2 adjust for age, education, socioeconomic status, marital status, work status at baseline (in 1968), and hypertension, CHD, stroke, diabetes mellitus, high waist-to-hip ratio, smoking and wine consumption (in 1968-80); and model 3 adjust for age and psychiatric family history (mental illness in mother, father and/or sibling is not included in number psychosocial stressors).

There may be several biological explanations for the association between psychosocial stressors in midlife and dementia. One is related to the stress hypothesis. Stress may cause a number of physiological reactions in the central nervous, endocrine, immune and cardiovascular systems. $^{10} 21$ Thus, psychological stress has been reported to increase the activity of the hypothalamicpituitary-adrenal axis and the levels of glucocorticoid hormones, ${ }^{22}$ cause structural and functional damage to the hippocampus, ${ }^{22}$ influence learning and memory processes, ${ }^{23}$ increase the production of proinflammatory cytokines in the brain, ${ }^{10}$ increase the deposition of $\beta$-amyloid peptid and $\tau$-protein in the brain ${ }^{24-26}$ and increase the frequency of cardiovascular disease ${ }^{27} 28$ and hypertension. ${ }^{29}$ All these factors have been linked to dementia. ${ }^{30}$

The associations between psychosocial stressors reported in midlife and perceived distress later in life was consistent through all follow-up years, as indicated by ORs of similar magnitude. Thus, even common psychosocial stressors (related to work and family) can cause distress over several decades. Our finding is supported by studies reporting that stress-hormones may remain elevated many years after traumatic events. ${ }^{8}$ Another explanation is that experiences of psychosocial traumas might make an individual more vulnerable to future stressors due to biological changes and dysfunctional stress coping mechanisms. ${ }^{31} 32$

\section{Strengths and weaknesses of the study}

The strengths of this study include midlife report of psychosocial stressors occurring long before the onset of dementia, the long follow-up period, the representative population and that multiple sources of information were used to detect and diagnose dementia. Some methodological issues need to be considered. First, the rating of stressors was related to the last year for some stressors and at any time before 1968 for other stressors. However, both these were related to the outcome in a similar way (data not shown). Second, some stressors were of a short duration, while others were chronic and lasted for many years. In addition, some stressors were severe and others more trivial. This might give an unbalanced weight among the factors studied. Third, we only have information on a limited number of psychosocial stressors in our population. Some events were not included, for example, physical abuse and own severe physical illness. The relationships might thus have been confounded by unmeasured factors. However, it is not likely that this had any major influence on our findings. Fourth, different individuals have varied capacities to cope with stress and thus react differently when exposed to the same stressor. We did not have an individual weighting of the included stressors. If anything, this might have decreased the strengths of associations. Fifth, some stressors are interrelated, for example, mental illness and alcohol abuse in spouse. However, these stressors independently increased stress reactions (data not shown). We, therefore, decided not to merge them. Sixth, distress in our study was based on self-report and we did not include an objective measure of stress reactions. However, most epidemiological studies use subjective report to assess stress or distress. Seventh, there are a number of risk factors occurring between baseline and development of dementia and these might potentially modify the association between common psychosocial

Table 4 Number of psychosocial stressors in 1968 in relation to incidence of dementia over 38 years

\begin{tabular}{lcllll}
\hline & Cases & & & & \\
& $\mathbf{n ~ ( \% )}$ & Model 1 & Model 2 & Model 3 & Model 4 \\
\hline All-type dementia & $153(19.1)$ & $1.15(1.05$ to 1.27$)$ & $1.16(1.04$ to 1.30$)$ & $1.10(1.00$ to 1.25$)$ & $1.13(1.01$ to 1.26$)$ \\
Vascular dementia & $35(4.4)$ & $0.94(0.75$ to 1.19$)$ & $0.97(0.75$ to 1.26$)$ & $0.79(0.57$ to 1.10$)$ & $0.93(0.71$ to 1.22$)$ \\
Alzheimer's disease & $104(13.0)$ & $1.21(1.08$ to 1.36$)$ & $1.21(1.06$ to 1.38$)$ & $1.16(1.00$ to 1.35$)$ & $1.17(1.02$ to 1.33$)$ \\
\hline
\end{tabular}

Cox regression analyses presented as HRs with 95\% Cls; model 1 adjust for age; model 2 adjust for age, education, socioeconomic status, marital status, work status at baseline (in 1968), and hypertension, CHD, stroke, diabetes mellitus, high waist-to-hip ratio, smoking, and wine consumption (in 1968-1980) and model 3 adjust for age and psychiatric family history (mental illness in mother, father and/or sibling is not included in number psychosocial stressors), and; model 4 adjust for age and long-standing distress (in 1968-1980). 
stressors in midlife and dementia. However, these risk factors would most likely decrease the possibility of finding associations in a study with the long follow-up, as may exert competing risk, and controlling for future factors might lead to an over-adjustment. Eighth, psychiatric family history may have an impact on the predisposition to distress and dementia. However, after adjusting for psychiatric family history (ie, mental illness in mother, father and/or sibling) the associations between the number of stressors was still associated with both long-standing distress, $\mathrm{AD}$ and all-type dementia. Ninth, cumulative attrition is a problem in the long-term follow-up studies. While this problem was, to some extent, alleviated by using medical records and the hospital registry data to diagnose dementia in those lost to follow-up, these sources probably underestimate the number of dementia cases. It should be noted, however, that almost all people in Sweden received their hospital treatment within the public healthcare system during the time of the study and that the Swedish Hospital Discharge Register covers the entire country. Furthermore, the number of demented women detected in the different age groups is what could be expected from other incidence studies. ${ }^{33}$ Finally, it is difficult to diagnose dementia subtypes on clinical grounds alone. Individuals with $\mathrm{AD}$ often have cerebrovascular disease and individuals with $\mathrm{VaD}$ often have concomitant $\mathrm{AD}$ pathology. Furthermore, cerebrovascular disease may influence the presence and severity of clinical symptoms of $\mathrm{AD}$, and vice versa. ${ }^{34}$ It is thus often difficult to make a clear distinction between $\mathrm{AD}$ and $\mathrm{VaD}$ in patients with a history of stroke or cerebrovascular disease, on clinical grounds and at autopsy, and mixed types are probably common.

\section{CONCLUSION}

To conclude, psychosocial stressors in midlife were associated with incidence of $\mathrm{AD}$ and long-standing distress, over several decades. This suggests that common psychosocial stressors may have severe and long-standing physiological and psychological consequences. However, more studies are needed to confirm these results and investigate whether more interventions such as stress management and behavioural therapy should be initiated in individuals who have experienced psychosocial stressors.

\section{Author affiliations \\ ${ }^{1}$ Neuropsychiatric Epidemiology Unit, Institute of Neuroscience and Physiology, Sahlgrenska Academy at Gothenburg University, Mölndal, Sweden ${ }^{2}$ Department of Clinical Neuroscience, Section for Psychiatry/Huddinge, Karolinska Institutet, Stockholm, Sweden \\ ${ }^{3}$ Department of Family Consumer and Human Development and Departments of Psychology, Utah State University, Logan, USA \\ ${ }^{4}$ Sahlgrenska School of Public Health and Community Medicine, Section for Public Health Epidemiology, The Sahlgrenska Academy at University of Gothenburg, Gothenburg, Sweden}

Acknowledgements The authors would like to thank all members of the Prospective Population Study of Women in Gothenburg study groups for their cooperation in data collection and management and Valter Sundh for statistical assistance.

Contributors All authors participated in the interpretation of data, wrote and critically reviewed the paper. LJ, XG and IS designed the study, generated the hypothesis, and wrote the draft. LJ did the analyses. All authors had full access to the data. LJ is the guarantor.

Funding The Swedish Medical Research Council; the Swedish Council for Working Life and Social Research; the Alzheimer's Association Zenith Award; the National Institutes of Health/National Institutes on Aging; the Alzheimer's Association Stephanie B. Overstreet Scholars The Bank of Sweden Tercentenary Foundation, Swedish Brain Power; Stiftelsen

Söderström-Königska Sjukhemmet; Stiftelsen för Gamla Tjänarinnor; Handlanden Hjalmar Svenssons Forskningsfond; Stiftelsen Professor Bror Gadelius' Minnesfond and the Sahlgrenska Academy, University of Gothenburg.

\section{Competing interests None.}

Ethics approval The Ethics Committee of Gothenburg University approved the study.

Provenance and peer review Not commissioned; externally peer reviewed.

Data sharing statement No additional data are available.

Open Access This is an Open Access article distributed in accordance with the Creative Commons Attribution Non Commercial (CC BY-NC 3.0) license, which permits others to distribute, remix, adapt, build upon this work noncommercially, and license their derivative works on different terms, provided the original work is properly cited and the use is non-commercial. See: http:// creativecommons.org/licenses/by-nc/3.0/

\section{REFERENCES}

1. Bremner JD, Randall P, Scott TM, et al. MRI-based measurement of hippocampal volume in patients with combat-related posttraumatic stress disorder. Am J Psychiatry 1995;152:973-81.

2. Sezgin U, Punamaki RL. Earthquake trauma and causal explanation associating with PTSD and other psychiatric disorders among South East Anatolian women. J Affect Disord 2012.

3. Yehuda R, Bierer LM, Schmeidler J, et al. Low cortisol and risk for PTSD in adult offspring of holocaust survivors. Am J Psychiatry 2000;157:1252-9

4. Norton MC, Ostbye T, Smith KR, et al. Early parental death and late-life dementia risk: findings from the Cache County Study. Age Ageing 2009;38:340-3.

5. Norton MC, Smith KR, Ostbye T, et al. Early parental death and remarriage of widowed parents as risk factors for Alzheimer disease: the Cache County study. Am J Geriatr Psychiatry 2011;19:814-24.

6. Persson G, Skoog I. A prospective population study of psychosocial risk factors for late onset dementia. Int J Geriatr Psych 1996;11:15-22.

7. Tsolaki M, Papaliagkas V, Kounti F, et al. Severely stressful events and dementia: a study of an elderly Greek demented population. Psychiatry Res 2010;176:51-4.

8. Yehuda R, Golier JA, Harvey PD, et al. Relationship between cortisol and age-related memory impairments in Holocaust survivors with PTSD. Psychoneuroendocrinology 2005;30:678-87.

9. Cacioppo JT, Burleson MH, Poehlmann KM, et al. Autonomic and neuroendocrine responses to mild psychological stressors: effects of chronic stress on older women. Ann Behav Med 2000;22:140-8.

10. Leonard BE. HPA and immune axes in stress: involvement of the serotonergic system. Neuroimmunomodulation 2006;13:268-76.

11. Johansson L, Guo X, Waern M, et al. Midlife psychological stress and risk of dementia: a 35-year longitudinal population study. Brain 2010;133(Pt 8):2217-24.

12. Johansson L, Skoog I, Gustafson DR, et al. Midlife psychologica distress associated with late-life brain atrophy and white matter lesions: a 32-year population study of women. Psychosom Med 2012;74:120-5.

13. Bengtsson $C$, Blohme $G$, Hallberg $L$, et al. The study of women in Gothenburg 1968-1969-a population study. General design, purpose and sampling results. Acta Med Scand 1973;193:311-18.

14. Lissner L, Skoog I, Andersson K, et al. Participation bias in Iongitudinal studies: experience from the Population Study of Women in Gothenburg, Sweden. Scand J Prim Health Care 2003;21:242-7. 
15. Skoog I, Nilsson L, Palmertz B, et al. A population-based study of dementia in 85-year-olds. N Engl J Med 1993;328:153-8.

16. Guo X, Waern M, Sjogren $\mathrm{K}$, et al. Midlife respiratory function and Incidence of Alzheimer's disease: a 29-year longitudinal study in women. Neurobiol Aging 2007;28:343-50.

17. Criteria for the clinical diagnosis of Alzheimer's disease. Excerpts from the NINCDS-ADRDA work group report. J Am Geriatr Soc 1985;33:2-3.

18. Roman GC, Tatemichi TK, Erkinjuntti T, et al. Vascular dementia: diagnostic criteria for research studies. Report of the NINDS-AIREN International Workshop. Neurology 1993;43:250-60.

19. Carlsson G. Socialgruppering. Social mobility and class structure. 1958

20. Rose GA. The diagnosis of ischaemic heart pain and intermittent claudication in field surveys. Bull World Health Organ 1962;27:645-58.

21. Buckley T, Sunari D, Marshall A, et al. Physiological correlates of bereavement and the impact of bereavement interventions. Dialogues Clin Neurosci 2012;14:129-39.

22. Sapolsky RM. Why stress is bad for your brain. Science 1996;273:749-50.

23. Csernansky JG, Dong $\mathrm{H}$, Fagan AM, et al. Plasma cortisol and progression of dementia in subjects with Alzheimer-type dementia. Am J Psychiatry 2006;163:2164-9.

24. Dong $\mathrm{H}$, Goico $\mathrm{B}$, Martin $\mathrm{M}$, et al. Modulation of hippocampal cell proliferation, memory, and amyloid plaque deposition in APPsw (Tg2576) mutant mice by isolation stress. Neuroscience 2004;127:601-9.

25. Kang JE, Cirrito JR, Dong $\mathrm{H}$, et al. Acute stress increases interstitial fluid amyloid-beta via corticotropin-releasing factor and neuronal activity. Proc Natl Acad Sci USA 2007;104:10673-8.
26. Green KN, Billings LM, Roozendaal B, et al. Glucocorticoids increase amyloid-beta and tau pathology in a mouse model of Alzheimer's disease. J Neurosci 2006;26:9047-56.

27. Pickering TG. Mental stress as a causal factor in the development of hypertension and cardiovascular disease. Curr Hypertens Rep 2001;3:249-54.

28. Folkow B, Hallback M, Weiss L. Cardiovascular responses to acute mental "stress" in spontaneously hypertensive rats. Clin Sci Mol Med Suppl 1973;45(Suppl 1):131s-3.

29. Sparrenberger F, Cichelero FT, Ascoli AM, et al. Does psychosocial stress cause hypertension? A systematic review of observational studies. J Hum Hypertens 2009;23:12-19.

30. Skoog I, Kalaria RN, Breteler MM. Vascular factors and Alzheimer disease. Alzheimer Dis Assoc Disord 1999;13(Suppl 3):S106-14.

31. McFarlane AC, Yehuda R, Clark CR. Biologic models of traumatic memories and post-traumatic stress disorder. The role of neural networks. Psychiatr Clin North Am 2002;25:253-70.

32. Westerlund H, Gustafsson PE, Theorell T, et al. Social adversity in adolescence increases the physiological vulnerability to job strain in adulthood: a prospective population-based study. PLOS ONE 2012;7:e35967.

33. Fratiglioni L, Launer LJ, Andersen $\mathrm{K}$, et al. Incidence of dementia and major subtypes in Europe: a collaborative study of population-based cohorts. Neurologic diseases in the elderly research group. Neurology 2000;54(11 Suppl 5):S10-15.

34. Snowdon DA, Greiner LH, Mortimer JA, et al. Brain infarction and the clinical expression of Alzheimer disease. The Nun Study. JAMA $1997 ; 277: 813-17$. 